\title{
Combination of a STAT3 Inhibitor and an mTOR Inhibitor Against a Temozolomide-resistant Glioblastoma Cell Line
}

\author{
HARUO MIYATA $^{1 *}$, TADASHI ASHIZAWA ${ }^{1 *}$, AKIRA IIZUKA ${ }^{1}$, RYOTA KONDOU ${ }^{1}$, CHIZU NONOMURA ${ }^{1}$, \\ TAKASHI SUGINO ${ }^{2}$, KENICHI URAKAMI $^{3}$, AKIRA ASAI $^{4}$, NAKAMASA HAYASHI $^{5}$, \\ KOICHI MITSUYA ${ }^{5}$, YOKO NAKASU $^{5}$, KEN YAMAGUCHI $^{6}$ and YASUTO AKIYAMA ${ }^{1,5}$ \\ ${ }^{1}$ Immunotherapy Division, ${ }^{3}$ Cancer Diagnostics Division, Shizuoka Cancer Center Research Institute, \\ ${ }^{2}$ Division of Pathology, ${ }^{5}$ Division of Neurosurgery, ${ }^{6}$ Office of the President, \\ Shizuoka Cancer Center Hospital, Shizuoka, Japan; \\ ${ }^{4}$ Graduate School of Pharmaceutical Sciences, University of Shizuoka, Shizuoka, Japan
}

\begin{abstract}
Background: Temozolomide-resistant (TMZ-R) glioblastoma is very difficult to treat, and a novel approach to overcome resistance is needed. Materials and Methods: The efficacy of a combination treatment of STAT3 inhibitor, STX0119, with rapamycin was investigated against our established TMZ-resistant U87 cell line. Results: The growth-inhibitory effect of the combination treatment was significant against the TMZ-R U87 cell line (IC 50 : $78 \mu M$ for STX-0119, $30.5 \mu M$ for rapamycin and $11.3 \mu \mathrm{M}$ for combination of the two). Western blotting analysis demonstrated that the inhibitory effect of STX-0119 on S6 and 4E-BP1 activation through regulation of $Y K L-40$ expression occurred in addition to the inhibitory effect of rapamycin against the mTOR pathway. Conclusion: These results suggest that the STAT3 pathway is associated with the mTOR downstream pathway mediated by YKL-40 protein, and the combination therapy of the STAT3 inhibitor and rapamycin could be worth developing as a novel therapeutic approach against TMZ-resistant relapsed gliomas.
\end{abstract}

This article is freely accessible online.

*These authors contributed equally to this study.

Abbreviations: GB: Glioblastoma, TMZ: temozolomide, MGMT: $\mathrm{O}^{6}$-methylguanine-O66-methylguanine-DNAmethyltransferase, STAT: signal transducer and activator of transcription, mTOR: mammalian target of rapamycin, shRNA: small hairpin RNA.

Correspondence to: Yasuto Akiyama, MD, Immunotherapy Division, Shizuoka Cancer Center Research Institute, 1007 Shimonagakubo, Nagaizumi-cho, Sunto-gun, Shizuoka 411-8777, Japan. Tel: +81 559895222 (Ext. 5330), Fax: +81 559896085, email: y.akiyama@scchr.jp

Key Words: STAT3 inhibitor, mTOR inhibitor, temozolomide resistance, glioblastoma.
Glioblastoma (GB) is one of the most malignant and aggressive tumors and has a very poor prognosis, with a mean survival time of less than 2 years even with the recent development of temozolomide (TMZ)-based intensive treatment $(1,2)$. Once recurrence develops, there are few therapeutic approaches to control the growth of glioblastoma. Therefore, TMZ-resistant GB is very difficult to treat, and a novel approach to overcome resistance is needed.

With regard to the mechanism of TMZ resistance, $\mathrm{O}^{6}$ methylguanine-DNA -methyltransferase (MGMT) removes methylation from the $\mathrm{O}^{6}$ position of guanine and contributes to $\mathrm{TMZ}$ resistance induction (3). It is generally accepted that high MGMT expression through the methylation of the MGMT promoter is one of the mechanisms responsible for TMZ resistance. Alternatively, several novel biomarkers linked to MGMT expression and the methylation status such as the HOX signature and epidermal growth factor receptor (EGFR) expression (4), somatic mutation of mismatch repair gene mutS homolog (MSH)6 (5), prolyl 4-hydroxylase, beta polypeptide (P4HB), EGFR mutation (EGFRvIII) (6), CD74 and signal transducer and activator of transcription (STAT)3 signaling have been reported. Kohsaka et al. reported the association of STAT3 expression with MGMT expression level using small interfering (si)RNA-mediated STAT3 gene inhibition (7).

Additionally, mammalian target of rapamycin (mTOR) signaling is activated in TMZ-resistant glioma cells as a result of EGFR, phosphoinositide 3 kinase (PI3K) and Akt signaling activation. mTOR is a Ser/Thr kinase that belongs to the phosphoinositide kinase-related family of protein kinases (PIKKs). mTOR acts as an essential integrator of growth-factor-activated and nutrient-sensing pathways to control and coordinate various cellular functions, including survival, proliferation, differentiation, autophagy and metabolism (8-11). More interestingly, Johnson et al. identified a novel mTOR-specific single nucleotide variant 
(SNV) in a clinical tumor specimen from TMZ-resistant glioma patients (12), which can contribute to mTOR signal activation in TMZ resistance.

Previously, we identified a novel inhibitor of STAT3 dimerization, STX-0119, that exhibited a potent anti-tumor effect on a TMZ-resistant U87 glioma cell line, and demonstrated that anti-tumor activity was partly mediated by a down-regulation of YKL-40 (13-15). In the present study, we focused on cancer signaling in the TMZ-resistant glioma cell line, in which the STAT3 and PI3K/Akt/mTOR pathways were highly activated, and investigated the effect of a combination therapy of the STAT3 inhibitor (STX-0119) and mTOR inhibitor (rapamycin) on a TMZ-resistant glioblastoma cell line in vitro and in vivo. We demonstrated that combination therapy effectively inhibited the proliferation of even a TMZ-resistant cell line through the possible association of the STAT3 and mTOR signaling pathways.

\section{Materials and Methods}

TMZ-resistant U87 cell line and antibodies. TMZ-resistant (R) U87 cells were established using a TMZ-dose-escalation method up to $150 \mu \mathrm{M}$, were maintained at a dose of $100 \mu \mathrm{M}$ TMZ and were used for in vitro and in vivo experiments (14). Antibodies against STAT3, phospho-STAT3 (Y705), cleaved caspase-3, EGFR, phospho-EGFR (Y845, Y1173), Ras, PI3 kinase p85, phospho-PI3 kinase p85 (Y458), Akt, phospho-Akt1 (S473), mTOR, phospho-mTOR (S2448), S6, phospho-S6 (S235, S236), 4E-BP1, phospho-4E-BP1 (T37, T46), B-Raf, phospho-B-Raf (S445), extracellular signalregulated kinase (ERK)1/2, mitogen-activated protein kinase (MAPK), phospho-ERK1/2 pMAPK (T202, Y204), p38 MAPK and phospho-p38 MAPK (T180, Y182) were purchased from Cell Signaling Technology, Inc. (Danvers, MA, USA) and BectonDickinson (BD) Biosciences (Franklin Lakes, NJ, USA) for Western blotting (WB). Mouse anti-human YKL-40 antibody was purchased from Abcam (Cambridge, MA, USA).

Chemicals. STX-0119 was supplied by the Center for Drug Discovery, University of Shizuoka (Shizuoka, Japan). These compounds were suspended and diluted in a sterile $0.5 \% \mathrm{w} / \mathrm{v}$ methyl cellulose $400 \mathrm{cp}$ solution (Wako, Tokyo, Japan) for use in animal experiments. TMZ and rapamycin were purchased from SIGMAALDRICH (St. Louis, MO, USA) and Selleck chemicals (Houston, TX, USA).

Cell proliferation assay. Cell proliferation was examined using the WST-1 assay (Dojin Kagaku Corp., Kumamoto, Japan) described previously (14). Briefly, $1 \times 10^{4}$ parental U87 or TMZ-R U87 cells were seeded into each well of a 96-well micro-culture plate (Corning, NY, USA) and compounds ranging from 0-200 $\mu \mathrm{M}$ were added alone or combination. After 4 days, the WST-1 substrate was added to the culture and optical density (OD) was measured at 450 and $620 \mathrm{~nm}$ using an immunoreader (Immuno Mini NJ-2300; Nalge Nunc International, Roskilde, Denmark). The $\mathrm{IC}_{50}$ value was defined as the dose needed for a 50\% reduction in OD calculated from the survival curve. Percent survival was calculated as follows: (mean O.D. of test wells - mean O.D. of background wells)/(mean O.D. of control wells - mean O.D. of background wells) $\times 100$.
Western blotting. TMZ-R U87 cells were treated with STX-0119 or rapamycin at the determined doses for $24 \mathrm{~h}$. The cells were lysed using RIPA buffer (Thermo Fisher Scientific Inc., Rockford, IL, USA) containing protease inhibitors and phosphatase inhibitors and used for western blotting as described previously (13). Briefly, cell lysate was subjected to SDS-PAGE with a $7.5 \%$ polyacrylamide separating gel, and then transferred to PVDF membranes. After blocking, the membranes were incubated at $4{ }^{\circ} \mathrm{C}$ overnight with various primary antibodies in blocking solution. After washing, the membranes were incubated for $1 \mathrm{~h}$ with horseradish peroxidase (HRP)-conjugated anti-mouse IgG. Membranes were treated with ECL plus reagent (GE Healthcare, Piscataway, NJ, USA) and analyzed on a chemiluminescence scanner (LAS-4000; GE Healthcare). Apoptosis induction in TMZ-R U87 cells treated with chemical reagents for $24 \mathrm{~h}$ was investigated using a Caspase-3 Western detection kit including the primary antibody against cleaved caspase-3 (Cell Signaling).

Inhibition of YKL-40 gene expression using shRNA transfection into TMZ-resistant U87 cells. The shRNA gene transfection into the TMZ-R U87 cell line was performed using a lipofection FreeStyle MAX reagent (Life Technology, Carlsbad, CA, USA) as reported previously (15). Briefly, YKL-40 shRNA-containing plasmid (SureSilencing shRNA vector; Qiagen GmbH, Hilden, Germany) and FreeStyle MAX reagent was suspended in optiMEM I reduced-serum medium (Life Technologies), that was then mixed and incubated for $15 \mathrm{~min}$ at room temperature (RT). The solution was added to $2 \times 10^{6}$ TMZ-resistant U87 cells, which were incubated in DMEM plus $10 \%$ FBS and utilized for in vitro experiments on day3. Similarly, plasmid pcDNA3.1 (Life Technologies) containing YKL-40 cDNA was transfected using lipofection into the parental U87 cell line, and transiently obtained U87 cells producing a high amount of YKL-40 protein were used for western blot analysis.

Animal experiments. Male nude mice (BALB/cA-nu/nu, 5-6 weeks old) were obtained from Nippon Clea (Tokyo, Japan). All of the animals were cared for and used humanely according to the guidelines for the welfare and use of animals in cancer research published in $\mathrm{Br} \mathrm{J}$ Cancer in 2010, and the procedures were approved by the Animal Care and Use Committee of Shizuoka Cancer Center Research Institute.

TMZ-R U87 cells $\left(1 \times 10^{6}\right)$ were inoculated into the flank of $\mathrm{BALB} / \mathrm{cA}-n u / n u$ mice. To evaluate the anti-tumor activity against subcutaneous (s.c.) inoculated tumors, tumor volume was calculated based on the National Cancer Institute formula as follows: tumor volume $\left(\mathrm{mm}^{3}\right)=$ length $(\mathrm{mm}) \times[\text { width }(\mathrm{mm})]^{2} \times 1 / 2$.

STX-0119 was administered orally daily from day 0 to day 4 followed by 2 day of rest ( 15 administrations at $40 \mathrm{mg} / \mathrm{kg}$ for 18 day). Rapamycin was administered intraperitoneally every other day followed by 2 days of rest ( 9 administrations at $4 \mathrm{mg} / \mathrm{kg}$ for 18 days). The efficacy of the treatment was expressed as the mean $V / V_{O}$ value or tumor/control ratio, where $V$ is the tumor volume on the day of evaluation and $V_{O}$ is the tumor volume on the day of treatment.

Whole-exome sequencing (WES) analysis of the TMZ-R U87 cell line using next-generation sequencing. WES was performed using an Ion Proton system with the AmpliSeq Exome kit as reported previously (16). Briefly, raw data were processed, filtered and 


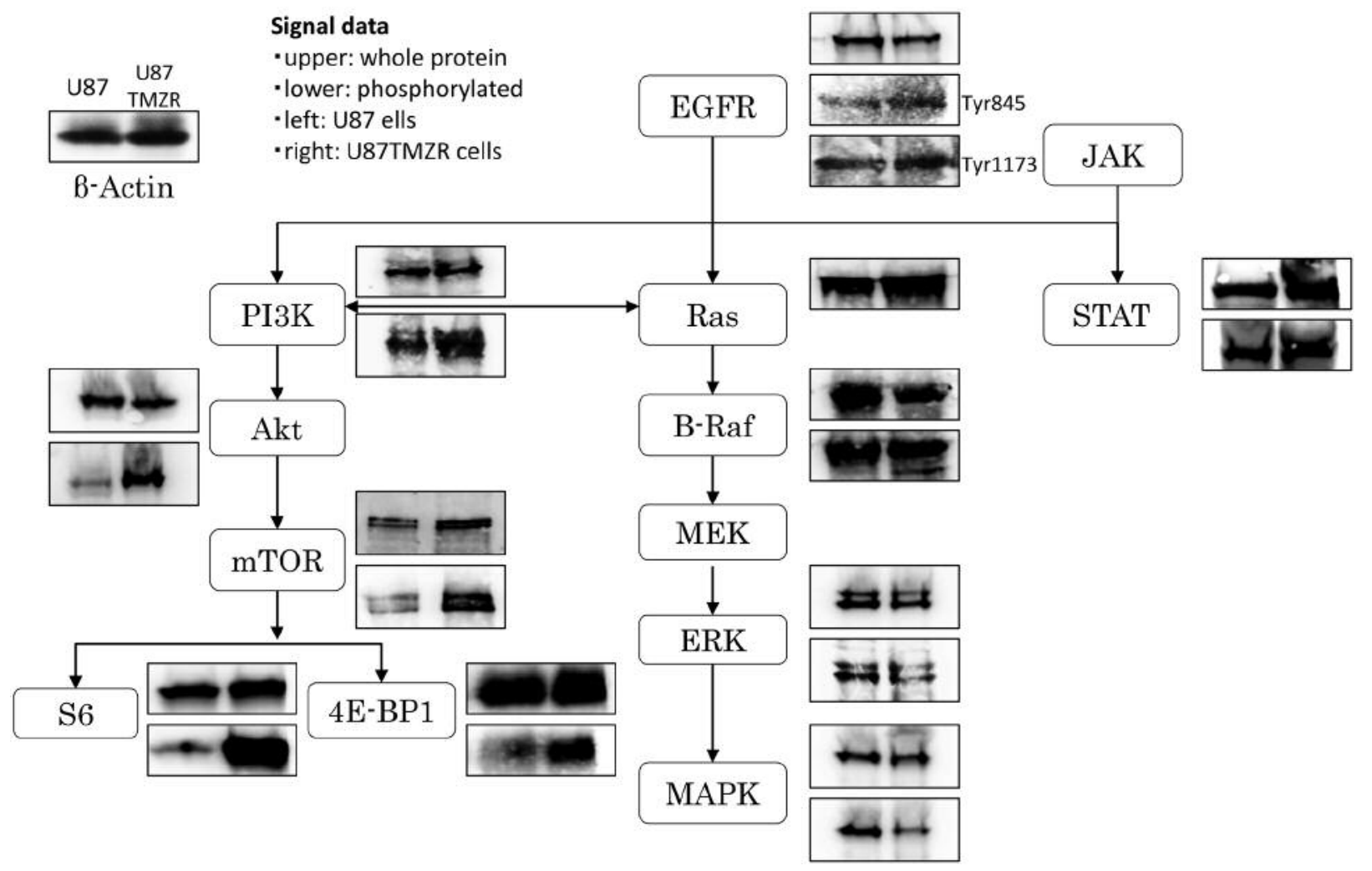

Figure 1. Cancer cell signaling profile in the TMZ-R U87 cell line. Cancer cell-associated signal molecules, such as EGFR, PI3K, Akt, mTOR, S6, 4E-BP1, Ras, Raf, ERK, MAPK and STAT3, were investigated using western blotting analysis. For each blot: Left, U87 parental cell line; right, TMZ-R U87 cell line; upper, whole protein; lower, phosphorylated protein.

converted to sequence reads by Torrent Suite Software and sequenced reads were mapped to the reference human genome (UCSC hg19) by tmap. Variant call was performed for each cell line separately by using Torrent Variant Caller. Quality $<30$, depth of coverage $<20$ and variant allele frequency $<10 \%$ were applied to filter out low quality mutations. The IonReporter tumor-normal workflow was applied to identify those mutations that were observed in the TMZ-R cell line only.

Statistical analysis. Statistical differences were analyzed using Student's $t$-test. Values of $p<0.05$ were considered statistically significant. For the in vivo experiment, statistical analysis was performed with corrected $p$-values to compare with the untreated control using Mann-Whitney's rank-sum test.

\section{Results}

Cancer signal pathway profiling of the TMZ-R U87 cell line. Phospho-EGFR, phospho-PIK3, phospho-Akt, phosphomTOR (S6 and 4E-BP1), and phospho-STAT3 signaling molecule protein levels were found up-regulated in TMZ-R U78 cells compared to the parental U87 cells (Figure 1). In contrast, the levels of the RAS downstream molecules phospho-raf, phospho-ERK, and phospho-MAPK were down-regulated.

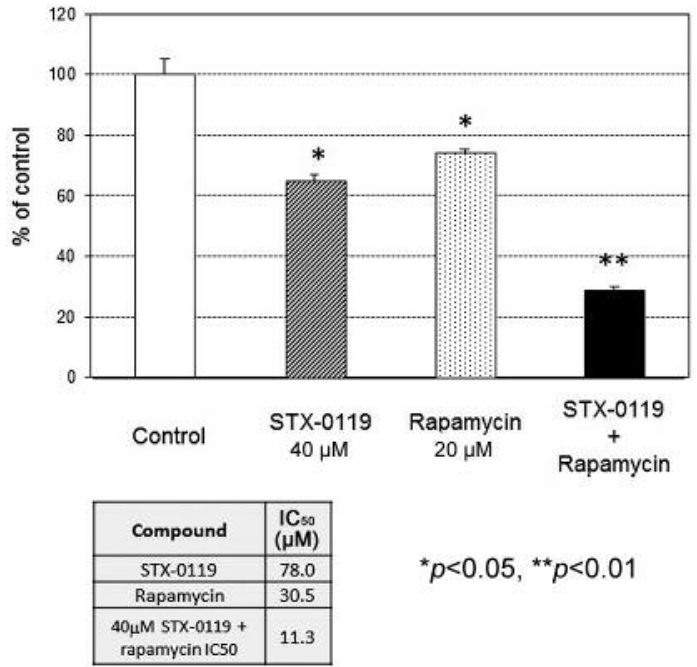

Figure 2. Effect of STX-0119 and/or rapamycin on the proliferation of the TMZ-R U87 cell line. The proliferation of the TMZ-R U87 cell line without treatment was designed 100 as a control, and the growthinhibitory effect of the drug was expressed as \% control. Each column shows the mean $\pm S D$ of triplicate samples. Open column: Control, shaded column: STX-0119, hatched column: rapamycin, closed column: STX-0119 and rapamycin. $* p<0.05, * * p<0.01$, statistically significant. 


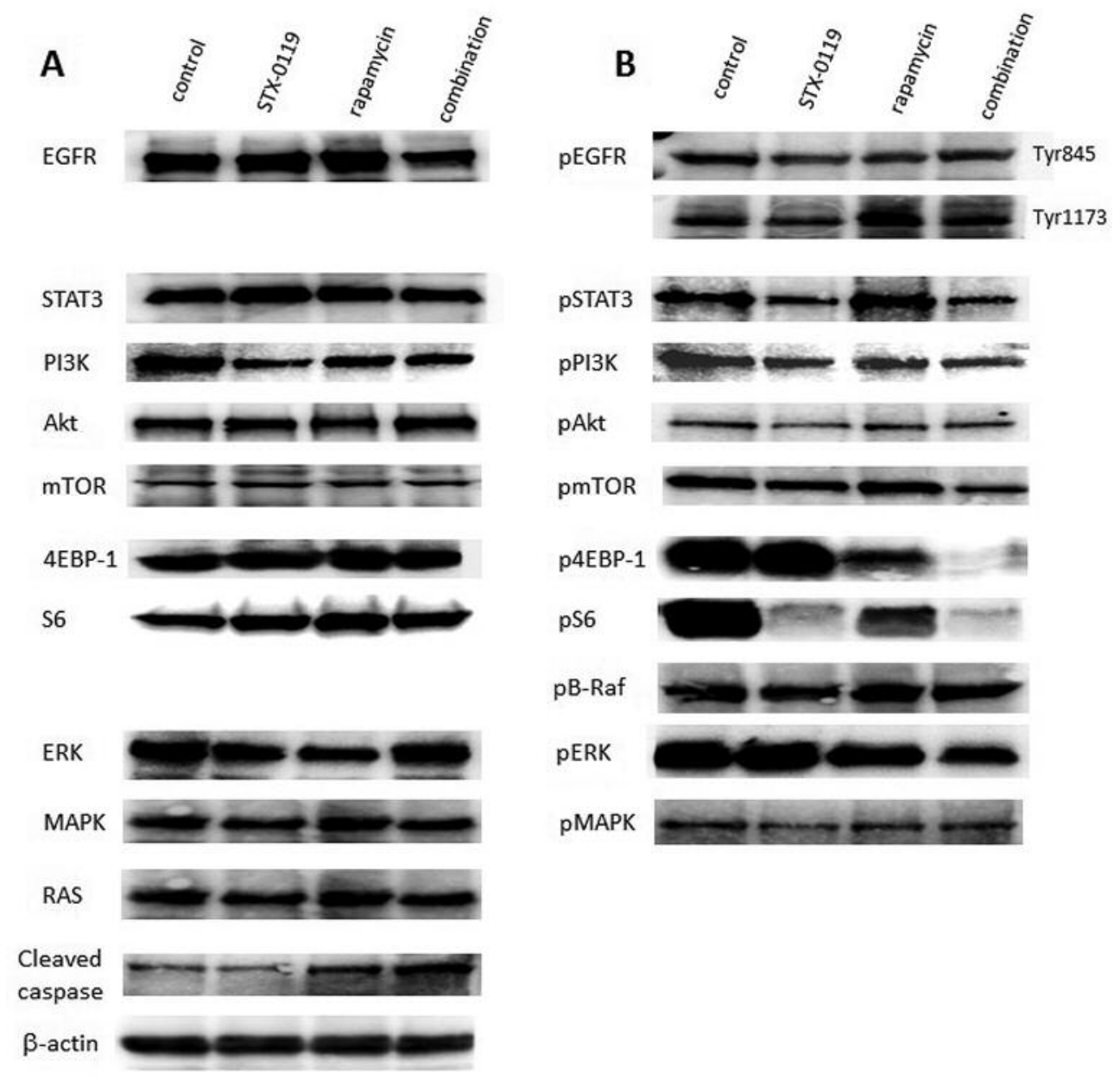

Figure 3. Effect of a combination treatment of STX-0119 and rapamycin on cancer cell signaling in the TMZ-R U87 cell line. The cells were treated with STX-0119 and/or rapamycin for $24 \mathrm{~h}$ and then used for WB analysis of cancer cell signaling molecules, such as EGFR, PI3K, Akt, mTOR, S6, 4E-BP1, HIF-1, Ras, Raf, ERK, MAPK and STAT3. (A) Whole proteins, (B) phosphorylated proteins.

Cell proliferation assay. STX-0119 and rapamycin displayed a moderate inhibitory effect on TMZ-R U87 cells $\left(\mathrm{STX}-0119 \mathrm{IC}_{50}=87 \mu \mathrm{M}\right.$, rapamycin $\left.\mathrm{IC}_{50}=30.5 \mu \mathrm{M}\right)$ (Figure 2). Remarkably, a combination of a suboptimal dose of STX-0119 $(40 \mu \mathrm{M})$ and rapamycin $(20 \mu \mathrm{M})$ significantly suppressed the proliferation of TMZ-R U87 cells by more than $70 \%$ compared to a single reagent $\left(\mathrm{IC}_{50}=11.3 \mu \mathrm{M}\right)$.

Effect of a combination treatment on signaling pathways of the TMZ-R U87 cell line. STX-0119 alone moderately inhibited the expression of both STAT3 and mTOR signaling molecules; however, rapamycin alone inhibited only mTOR. Remarkably, a combination of STX-0119 and rapamycin at $40 \mu \mathrm{M}$ and $20 \mu \mathrm{M}$, respectively, significantly suppressed STAT3 and PI3K/Akt/mTOR signaling molecule levels (Figure 3).
Apoptosis induction by a combination of STX-0119 with rapamycin in TMZ-R U87 cell line. Cleaved caspase-3 expression increased in TMZ-R U87 cells treated with rapamycin. Additionally, a combination of STX-0119 and rapamycin demonstrated the highest increase of cleaved caspase-3 expression in TMZ-R U87 cells (Figure 3).

Impact of the regulation of $Y K L-40$ gene expression on PIK3/Akt/mTOR signaling. YKL-40 mRNA inhibition by shRNA inhibited mTOR and 4E-BP1, but not S6. Alternatively, YKL-40 overexpression in the parental U87 cells using YKL-40 cDNA transduction induced a significant up-regulation of the S6 signaling molecule. In contrast, mTOR phosphorylation was inhibited (Figure 4).

Effect of the combination of STX-0119 with rapamycin on TMZR U87 tumor growth in vivo. TMZ-R U87 cell- 


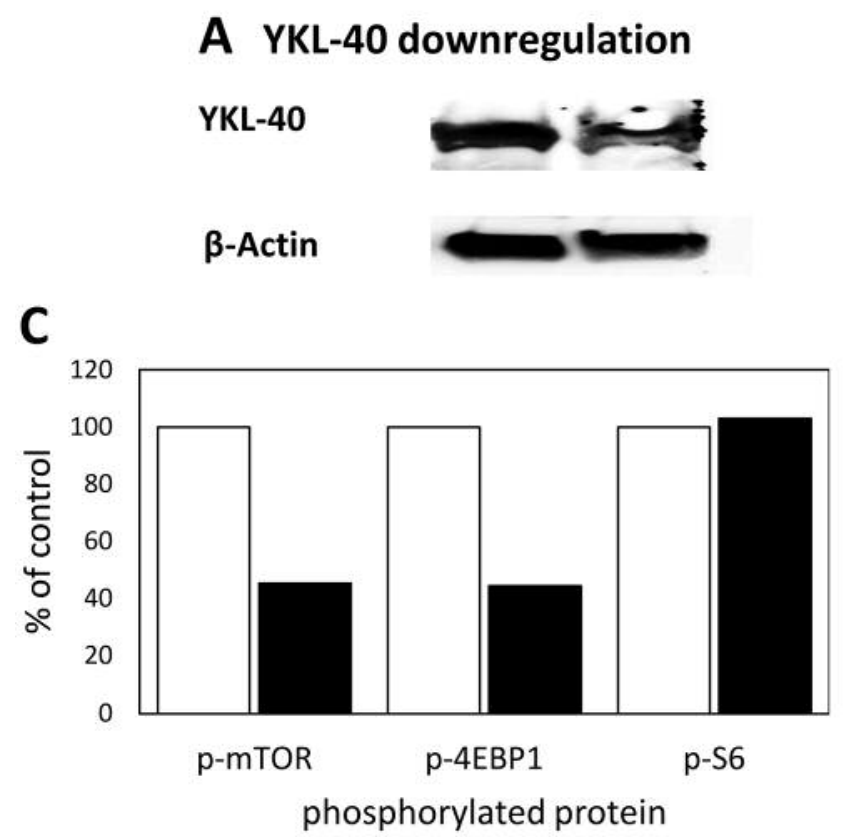

B YKL-40 upregulation

YKL-40

$\beta$-Actin

D

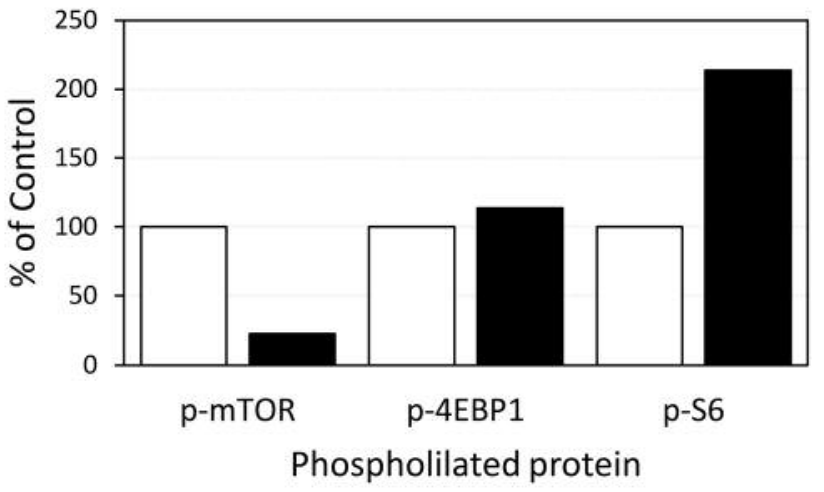

STX-0119

E

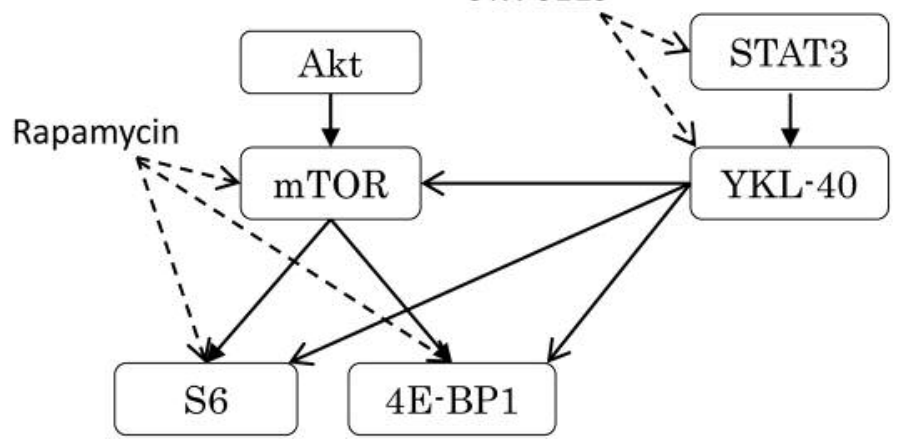

Figure 4. Impact of YKL-40 expression level on mTOR pathway signals. The expression levels of mTOR, S6 and $4 E-B P 1$ phosphoproteins were investigated in the case of (A) YKL-40-downregulation (TMZ-R U87 cells) or (B) YKL-40-upregulation (U87 parental cells). At the bottom, each phosphoprotein level is shown as \% of control (C) Open column: Control, closed column: YKL-40 down-regulated by shRNA, (D) Open column: control, closed column:YKL-40 overexpressed by gene transfection. (E) A speculated pathways between STAT3-YKL-40 and mTOR signaling. Solid line: Stimulating signal, dashed line: inhibiting signal.

transplanted mice showed significant resistance to TMZ and a shorter survival time in vivo compared to the parental U87 cell line, as shown in our previous study (14). STX-0119 alone showed a moderate inhibitory effect on TMZR U87 tumor growth in nude mice. In contrast, rapamycin alone exhibited improved growth inhibition of TMZR U87 tumors. Therefore, a combination of STX-0119 with rapamycin did not show a significant additive effect on TMZR U87 tumor growth (Figure 5).

Whole-exome sequencing (WES) analysis of the TMZ-R U87 cell line. The number of mutated genes and SNVs per cell line was 9,533 and 22,824 in the U87 parental cell line and 11,837 and 30,872 in the U87 TMZ-R cell line, respectively. U87 TMZ-R cell-specific SNVs related to cancer signaling pathwayassociated genes are shown in Table I. The number of nonsynonymous SNVs detected per cell line was 389 in the U87 parental and 686 in the U87 resistant cell line. U87 TMZ-R cellspecific SNVs were found in the EGFR, PIK3C3, STAT1, STAT2, STAT6 and YKL-40 (CHI3L1) genes. Interestingly, a somatic mutation of the EGFR C-terminal domain (E1004K) was verified. Additionaly, an adjacent mutation (ER1005$1006 \mathrm{KD})$ was reported to induce spontaneous activation of EGFR phosphorylation (17). Alternatively, a somatic mutation of the YKL-40 gene (G292R) was also found, but it was unlikely to be functional in signal transduction. 
A
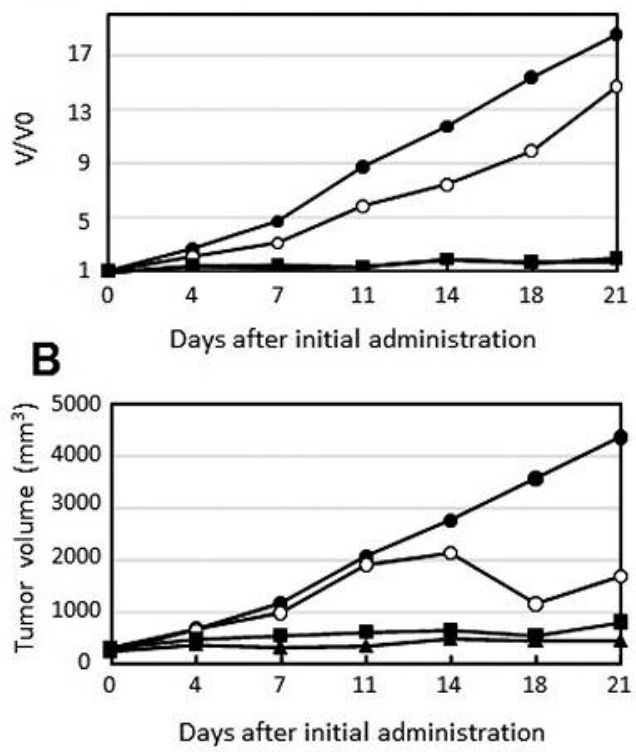

C


Figure 5. Inhibitory effect of STX-0119 and/or rapamycin on in vivo tumor growth of TMZ-R U87 cells. Nude mice transplanted with TMZ-R U87

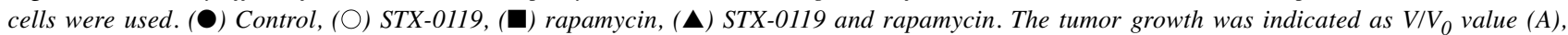
actual tumor volume $(B)$ or tumor/control ratio (\%) (C). To evaluate adverse effects, the change in body weight is shown in (D). Each point shows the mean value of 5 mice.

Table I. U87-TMZR signaling-associated SNV gene list.

\begin{tabular}{|c|c|c|c|c|c|c|c|}
\hline Chrom & Position & Ref & Var & Gene ID & UniProt acc & Gene symbol & SnpEff prediction \\
\hline \multicolumn{8}{|c|}{ U87 TMZR cell-associated mutation } \\
\hline chr7 & 55268944 & G & A & 1956 & P00533 & $E G F R$ & missense:Gaa/Aaa:E1004K \\
\hline $\operatorname{chr} 18$ & 39595517 & G & A & 5289 & Q8NEB9 & $P I K 3 C 3$ & missense:gGc/gAc:G468D \\
\hline $\operatorname{chr} 3$ & 178937024 & $\mathrm{C}$ & $\mathrm{T}$ & 5290 & P42336 & $P I K 3 C A$ & missense:Ctt/Ttt:L569F \\
\hline chr10 & 102296366 & $\mathrm{C}$ & $\mathrm{T}$ & 55662 & Q9NWT6 & $H I F 1 A N$ & missense:Cat/Tat:H126Y \\
\hline $\operatorname{chr} 9$ & 5069121 & $\mathrm{G}$ & A & 3717 & O60674 & $J A K 2$ & missense:Gat/Aat:D476N \\
\hline $\operatorname{chr} 2$ & 191839582 & $\mathrm{C}$ & $\mathrm{T}$ & 6772 & $\mathrm{P} 42224$ & STAT1 & missense:Gtg/Atg:V738M \\
\hline $\operatorname{chr} 2$ & 191855954 & $\mathrm{C}$ & $\mathrm{T}$ & 6772 & P42224 & STAT1 & missense:aGa/aAa:R346K \\
\hline $\operatorname{chr} 12$ & 56745161 & $\mathrm{C}$ & $\mathrm{T}$ & 6773 & P52630 & STAT2 & missense:Gtt/Att:V282I,V286I \\
\hline $\operatorname{chr} 12$ & 57496113 & $\mathrm{G}$ & A & 6778 & P42226 & STAT6 & missense:gCc/gTc:A381V,A491V \\
\hline $\operatorname{chr} 1$ & 203149618 & $\mathrm{C}$ & $\mathrm{T}$ & 1116 & P36222 & CHI3LI & missense:Ggg/Agg:G292R \\
\hline $\operatorname{chr} 22$ & 51042359 & $\mathrm{C}$ & $\mathrm{T}$ & 23542 & Q13387 & $M A P K 8 I P 2$ & missense:Cct/Tct:P184S,P211S \\
\hline
\end{tabular}

\section{Discussion}

Glioblastomas are the most malignant and aggressive of tumors and have a very poor prognosis and a high recurrence rate, with a less than $5 \%$ survival rate at 2 years.

Frequent recurrence even after chemo-radiation treatment is a crucial problem in the clinical field, which must be overcome to extend the overall survival of GBM patients. Recently, genomic studies using exome-based clinical sequencing revealed tumor-specific genetic alterations according to the tumor development stage from primary to relapse as follows; loss of heterozygosity (LOH) 10q (69\%), EGFR amplification (34\%), TP53 mutation (31\%), p16 (INK4a) deletion $(31 \%)$ and phosphatase and tensin homolog deleted on chromosome ten (PTEN) mutations (24\%) in primary glioblastomas which account for $95 \%$ of all glioblastomas $(18,19)$.

PTEN is a phosphatase that was, originally identified as a tumor suppressor gene and is frequently altered in a variety of human cancers, such as brain, breast and prostate $(20,21)$; 
these alterations lead to deregulation of protein synthesis, the cell cycle, migration, growth, DNA repair and survival signaling. PTEN inactivation by deletion and mutations occurs in approximately $40 \%$ of glioblastoma patients. PTEN inactivation is known to induce PI3K/Akt/mTOR signal activation in various tumors. Targeting these pathways is often complex and can result in pathway activation depending on the presence of upstream mutations $(22,23)$. In glioblastomas, PTEN inactivation-based mTOR signal activation is frequently seen together with PI3K mutationbased amplification; therefore, those tumors are more sensitive to mTOR inhibitors $(24,25)$. Additionally, as for mTOR activation in glioblastomas, Pelloski et al. showed that higher expression of phospho (p)-mTOR, p-70S6K and p-MAPK was associated with worse outcome, as shown by immunohistochemical staining in 268 cases of newly diagnosed glioblastomas. Importantly, Cloughesy et al. reported anti-tumor activity of the mTOR inhibitor rapamycin in a phase I trial for patients with recurrent PTEN-deficient glioblastomas; however, the result of the trial was disappointing (25).

Cell signaling profiling of TMZ-R U87 cells using WB analysis demonstrated that p-EGFR, p-PIK3, p-Akt, p-mTOR (S6 and 4E-BP1), and phosho-STAT3 signaling protein levels were up-regulated in TMZ-R U87 cells compared to parental U87 cells. These results seemed to be similar to the observation verified in TMZ-resistant glioma cells or tissues $(11,23)$. The inhibitory effect of rapamycin seemed to be efficient but was restricted to p-mTOR and p-70S6, and did not affect the p-PIK3 or p-Akt proteins. STX-0119 was specific and potent for p-STAT3, and the inhibitory effect on p-mTOR and p-Akt protein was positive but moderate. Remarkably, a combination of rapamycin with STX-0119 diminished both PI3K/Akt/mTOR and STAT3 signaling and significantly suppressed the growth of TMZ-R U87 cells.

The signaling relationship between mTOR and STAT3 has been suggested in a few studies regarding mTOR inhibitor development (26-28). Specifically, Hu et al. (27) identified brain-expressed X-linked 2 (BEX2), a novel downstream molecule of the mTOR pathway; they found that mTOR signal activation can be mediated by BEX2 and transmitted to the STAT3 and NF-kB pathways. Oroxylin, a natural monoflavonoid, reported by Zou et al., inhibited Akt and ERK activation and the downstream phosphorylation of mTOR and STAT3, which was mediated by Beclin 1, a key autophagyrelated protein (28). Our shRNA-mediated gene inhibition study showed that both STAT3 and YKL-40 gene inhibition suppressed mTOR signaling; however, inhibition of the mTOR signaling pathway was greater when YKL-40 was inhibited (data not shown); this result suggests that mTOR is located downstream of the STAT3/YKL-40 pathway, because STAT3 signal inhibition by STX-0119 resulted in a significant reduction of the YKL-40 protein level in our previous study (14).
Another important issue regarding mTOR signal activation in TMZ-R U87 cells is genetic alteration of the mTOR gene (29-31). Briefly, three studies regarding mTOR mutation research have been cited. Sato et al. identified two mTOR point mutations ( $22215 \mathrm{Y}$ and R2505P) out of 750 cancer samples from the COSMIC library; however, these mutations were not functional (29). Gerlinger et al. identified a tumor-specific functional mTOR mutation (L2431P) from four cases of metastatic renal cancer that showed mTOR kinase activation with S6 and 4EBP phosphorylation (30). Finally, Johnson et al. reported that a novel mTOR mutation (S2215F) was identified in relapsed secondary glioblastoma tissue, which induced p-RPS6 and p-4EBP1 activation (12).

Our whole-exome sequencing of TMZ-R U87 cells revealed that tumor-specific SNVs (non-synonymous mutations) were identified, and some SNVs belonged to the Vogelstein cancer driver gene group. The list of genes that were specifically mutated in TMZ-resistant U87 cells contained EGFR, PIK3CA, MSH2, ARID1A, PRDM1, and SMARCA4, some of which had already been reported in relapsed glioblastoma tissue (data not shown). However, specific mTOR mutations were not recognized, as demonstrated by Johnson et al. (12). Interestingly, a novel mutation (E1004K) located in the C-terminal tail domain of EGFR was found in Table I. Considering that the N-terminal half of the EGFR C-terminal tail domain has an inhibitory function in EGFR signal activation (31) and that a neighboring mutation (ER1005-1006KD) was reported to induce spontaneous activation of EGFR phosphorylation (17), this mutation (E1004K) might be involved in EGFR signaling. Alternatively, a novel somatic mutation of the YKL-40 gene (G292R) was also found, but it likely dose not function in signal transduction.

In contrast to the in vitro study, the in vivo study of a combination treatment of STX-0119 and rapamycin against TMZ-R U87 tumors did not show a significant additive inhibitory effect. There is a concern regarding the dose of rapamycin used in the in vivo study. Mukhopadhyay et al. (32) demonstrated the enigma of rapamycin dosage: a low dose of rapamycin inhibits mainly S6 phosphorylation, and a high dose inhibits both S6 and 4E-BP1 phosphorylation. Therefore, different doses of rapamycin can be investigated to identify the optimal combination for in vivo study.

The present study is the first report of a successful combination therapy of an mTOR inhibitor and a STAT3 inhibitor against TMZ-R glioblastoma cells in vitro. Additionally, we made the novel observation of an association between mTOR and STAT3 signaling that is mediated by the YKL-40 protein (Figure 4E). Considering that novel dual or triple inhibitor development against PI3K/Akt/mTOR signal activation has been in progress since the development of rapalogs, everolimus and temsirolimus (33-38), the novel 
effective combination of an mTOR inhibitor and a STAT3 inhibitor shown in the present study deserves attention as a novel therapeutic approach against relapsed TMZ-resistant glioblastomas.

\section{Conflicts of Interest}

The Authors have no competing interests to declare.

\section{Acknowledgements}

The Authors thank Drs Nagashima and Shimoda, Cancer Diagnostics Division, Shizuoka Cancer Center Research Institute for excellent technical support for whole-exome sequencing of glioma cell lines.

\section{References}

1 Stupp R, Mason WP, van den Bent MJ, Weller M, Fisher B, Taphoorn MJ, Belanger K, Brandes AA, Marosi C, Bogdahn U, Curschmann J, Janzer RC, Ludwin SK, Gorlia T, Allgeier A, Lacombe D, Cairncross JG, Eisenhauer E and Mirimanoff RO: Radiotherapy plus concomitant and adjuvant temozolomide for glioblastoma. N Engl J Med 352(10): 987-996, 2005.

2 Mirimanoff RO, Gorlia T, Mason W, Van den Bent MJ, Kortmann RD, Fisher B, Reni M, Brandes AA, Curschmann J, Villa S, Cairncross G, Allgeier A, Lacombe D and Stupp R: Radiotherapy and temozolomide for newly diagnosed glioblastoma: recursive partitioning analysis of the EORTC 26981/22981-NCIC CE3 phase III randomized trial. J Clin Oncol 24(16): 2563-2569, 2006.

3 Hegi ME, Diserens AC, Gorlia T, Hamou MF, de Tribolet N, Weller M, Kros JM, Hainfellner JA, Mason W, Mariani L, Bromberg JE, Hau P, Mirimanoff RO, Cairncross JG, Janzer $\mathrm{RC}$ and Stupp R: $M G M T$ gene silencing and benefit from temozo-lomide in glioblastoma. N Engl J Med 352(10): $997-$ 1003, 2005.

4 Murat A, Migliavacca E, Gorlia T, Lambiv WL, Shay T, Hamou MF, de Tribolet N, Regli L, Wick W, Kouwenhoven MC, Hainfellner JA, Heppner FL, Dietrich PY, Zimmer Y, Cairncross JG, Janzer RC, Domany E, Delorenzi M, Stupp R and Hegi ME: Stem cell-related "self-renewal" signature and high epidermal growth factor receptor expression associated with resistance to concomitant chemoradiotherapy in glioblastoma. J Clin Oncol 26(18): 3015-3024, 2008.

5 Xie C, Sheng H, Zhang N, Li S, Wei X and Zheng X: Association of MSH6 mutation with glioma susceptibility, drug resistance and progression. Mol Clin Oncol 5(2): 236-240, 2016.

6 Camorani S, Crescenzi E, Colecchia D, Carpentieri A, Amoresano A, Fedele M, Chiariello M and Cerchia L: Aptamer targeting EGFRvIII mutant hampers its constitutive autophosphorylation and affects migration, invasion and proliferation of glioblastoma cells. Oncotarget 6(35): 3757037587, 2015.

7 Kohsaka S, Wang L, Yachi K, Mahabir R, Narita T, Itoh T, Tanino M, Kimura $\mathrm{T}$, Nishihara $\mathrm{H}$ and Tanaka S: STAT3 inhibition overcomes temozolomide resistance in glioblastoma by donregulating MGMT expression. Mol Cancer Ther 11(6): 1289-1299, 2012.
8 Majewska E and Szeliga M: AKT/GSK3 $\beta$ signaling in glioblastoma. Neurochem Res 2016. DOI: 10.1007/s11064-016-2044-4.

9 Lin F, de Gooijer MC, Hanekamp D, Chandrasekaran G, Buil L, Thota N, Sparidans RW, Beijnen JH, Wurdinger T and van Tellingen O: PI3K-mmTOR pathway inhibition exhibits efficacy against high-grade glioma in clinically relevant mouse models. Clin Cancer Res 2016. DOI: 10.1158/1078-0432.CCR-16-1276.

10 Neshat MS, Mellinghoff IK, Trans C, Stiles B, Petersen R, Frost P, Gibbons JJ, Wu H and Sawyers CL: Enhanced sensitivity of PTEN-deficient tumors to inhibition of FRAP/mTOR. Proc Natl Acad Sci USA 98(18): 10314-10319, 2001.

11 McCubrey JA, Steelman LS, Chappell WH, Abrams SL, Montalto G, Cervello M, Nicoletti F, Fagone P, Malaponte G, Mazzarino MC, Candido S, Libra M, Basecke J, Mijatovic S, Maksimovic-Ivanic D, Milella M, Tafuri A, Cocco L, Evangelisti $\mathrm{C}$, Chiarini $\mathrm{F}$ and Martelli AM: Mutations and deregulation of Ras/Raf/MEK/ERK and PI3K/PTEN/Akt/mTOR cascades which alter therapy response. Oncotarget 3(9): 954-987, 2012.

12 Johnson BE, Mazor T, Hong C, Barnes M, Aihara K, McLean CY, Fouse SD, Yamamoto S, Ueda H, Tatsuno K, Asthana S, Jalbert LE, Nelson SJ, Bollen AW, Gustafson WC, Charron E, Weiss WA, Smirnov IV, Song JS, Olshen AB, Cha S, Zhao Y, Moore RA, Mungall AJ, Jones SJ, Hirst M, Marra MA, Saito N, Aburatani H, Mukasa A, Berger MS, Chang SM, Taylor BS and Costello JF: Mutational analysis reveals the origin and therapy-driven evolution of recurrent glioma. Science 343(6167): 189-193, 2014.

13 Ashizawa T, Miyata H, Ishii H, Oshita C, Matsuno K, Masuda Y, Furuya T, Okawara T, Otsuka M, Ogo N, Asai A and Akiyama Y: Antitumor activity of a novel small molecules STAT3 inhibitor against a human lymphoma cell line with high STAT3 activation. Int J Oncol 38(5): 1245-1252, 2011.

14 Ashizawa T, Akiyama Y, Miyata H, Iizuka A, Komiyama M, Kume A, Omiya M, Sugino T, Asai A, Hayashi N, Mitsuya K, Nakasu Y and Yamaguchi K: Effect of the STAT3 inhibitor STX0119 on the proliferation of a temozolomide-resistant glioblastoma cell line. Int J Oncol 45(1): 411-418, 2014.

15 Akiyama Y, Ashizawa T, Komiyama M, Miyata H, Oshita C, Omiya M, Iizuka A, Kume A, Sugino T, Hayashi N, Mitsuya K, Nakasu Y and Yamaguchi K: YKL-40 down-regulation is a key factor to overcome temozolomide resistance in a glioblastoma cell line. Oncol Rep 32(1): 159-166, 2014.

16 Urakami K, Shimoda Y, Ohshima K, Nagashima T, Serizawa M, Tanabe T, Saito J, Usui T, Watanabe Y, Naruoka A, Ohnami S, Ohnami S, Mochizuki T, Kusuhara M and Yamaguchi K: Next generation sequencing approach for detecting 491 fusion genes from human cancer. Biomed Res 37(1): 51-62, 2016.

17 Jura N, Endres NF, Engel K, Deindl S, Das R, Lamers MH, Wemmer DE, Zhang X and Kuriyan J: Mechanism for activation of the EGF receptor catalytic domain by the juxtramembrane segment. Cell 137(7): 1293-1307, 2009.

18 Ohgaki H, Dessen P, Jourde B, Horstmann S, Nishikawa T, Di Patre PL, Burkhard C, Schüler D, Probst-Hensch NM, Maiorka PC, Baeza N, Pisani P, Yonekawa Y, Yasargil MG, Lütolf UM and Kleihues P: Genetic pathways to glioblastoma:a populationbased study. Cancer Res 64(19): 6892-6899, 2004.

19 Carro MS, Lim WK, Alvarez MJ, Bollo RJ, Zhao X, Snyder EY, Sulman EP, Anne SL, Doetsch F, Colman H, Lasorella A, Aldape $\mathrm{K}$, Califano A and Lavarone A: The transcriptional network for mesenchymal transformation of brain tumors. Nature 463(7279): 318-325, 2010. 
20 Hopkins BD, Hodakoski C, Barrows D, Mense SM and Parsons RE: PTEN function:the long and the short of it. Trends Biochem Sci 39(4): 183-190, 2014.

21 Keniry $M$ and Parsons R: The role of PTEN signaling perturbations in cancer and in targeted therapy. Oncogene 27(41): 5477-5485, 2008.

22 Podsypanina K, Lee RT, Politis C, Hennessy I, Crane A, Puc J, Neshat M, Wang H, Yang L, Gibbons J, Frost P, Dreisbach V, Blenis J, Gaciong Z, Fisher P, Sawyers C, Hedrick-Ellenson L and Parsons R: An inhibitor of mTOR reduces neoplasia and normalizes p70/S6 kinase activity in PTEN+/- mice. Proc Natl Acad Sci USA 98(18): 10320-10325, 2001.

23 McCubrey JA, Steelman LS, Chappell WH, Abrams SL, Franklin RA, Montalto G, Cervello M, Libra M, Candido S, Malaponte G, Mazzarino MC, Fagone P, Nocoletti F, Bäsecke J, Mijatovic M, Maksimovic-Ivanic D, Milella M, Tafuri A, Chiarini F, Evangelisti C, Cocco L, Martelli AM: Ras/Raf/MEK/ERK and PI3K/PTEN/Akt/mTOR cascade inhibitors:how mutations can result in therapy resistance and how to overcome resistance. Oncotarget 3(10): 1068-1111, 2012.

24 Lee JJ, Kim BC, Park MJ, Lee YS, Kim YN, Lee BL and Lee JS: PTEN status switches cell fate between premature senescence and apoptosis in glioma exposed to ionizing radiation. Cell Death Differ 18(4): 666-677, 2011.

25 Cloughesy TF, Yoshimoto K, Nghiemphu P, Brown K, Dang J, Zhu S, Hsueh T, Chen Y, Wang W, Youngkin D, Liau L, Martin N, Becker D, Bergsneider M, Lai A, Green R, Oglesby T, Koleto M, Trent J, Horvath S, Mischel PS, Mellinghoff IK and Sawyers CL: Antitumor activity of rapamycin in a Phase I trial for patients with recurrent PTEN-deficient glioblastoma. PLoS Med 5(1): e8, 2008.

26 Cheng W, Zhang C, Ren X, Jiang Y, Han S, Liu Y, Cai J, Li M, Wang K, Liu Y, Hu H, Li Q, Yang P, Bao Z and Wu A: Bioinformatic analyses reveal a distinct Notch activation induced by STAT3 phosphorylation in the mesenchymal subtype of glioblastoma. J Neurosurg 2016. DOI: 10.3171/2015.11.jns 15432.

$27 \mathrm{Hu} \mathrm{Z}$, Wang Y, Huang F, Chen R, Li C, Wang F, Goto J, Kwiatkowski DJ, Wdzieczak-Bakala J, Tu P, Liu J, Zha X and Zhang H: Brain-expressed X-linked 2 is pivotal for heperactive mechanistic target of rapamycin (mTOR)-mediated tumorigenesis. J Biol Chem 290(42): 25756-25765, 2015.

28 Zou M, Hu C, You Q, Zhang A, Wang X and Guo Q: Oroxylin A induces autophagy in human malignant glioma cells via the mTOR-STAT3-Notch signaling pathway. Mol Carcinog 54(11): 1363-1375, 2015.

29 Sato T, Nakashima A, Guo L, Coffman K and Tamanoi F: Single amino-acid changes that confer constitutive activation of mTOR are discovered in human cancer. Oncogene 29(18): 2746-2752, 2010 .
30 Gerlinger M, Rowan AJ, Horswell S, Larkin J, Endesfelder D, Gronroos E, Martinez P, Matthews N, Stewart A, Tarpey P, Varela I, Phillimore B, Begum S, McDonald NQ, Butler A, Jones D, Raine K, Latimer C, Santos CR, Nohadani M, Eklund AC, Spencer-Dene B, Clark G, Pickering L, Stamp G, Gore M, Szallasi Z, Downward J, Futreal PA and Swanton C: Intratumor heterogeneity and branched evolution revealed by multiregion sequencing. N Engl J Med 366(10): 883-892, 2012.

31. Kovacs E, Das R, Wang Q, Collier TS, Cantor A, Huang Y, Wong K, Mirza A, Barros T, Grob P, Jura N, Bose R and Kuriyan J: Analysis of the role of the C-terminal tail in the regulation of the epidermal growth factor receptor. Mol Cell Biol 35(17): 3083-3102, 2015.

32 Mukhopadhyay S, Frias MA, Chatterjee A, Yellen P and Faoter DA: The enigma of rapamycin dosage. Mol Cancer Ther 15(3): 347-353, 2016.

33 Grabiner BC, Nordi V, Birsoy K, Possemato R, Shen K, Sinha S, Jordan A, Beck AH and Sabatini DM: A diverse array of cancerassociated MTOR mutations are hyperactivating and can predict rapamycin sensitivity. Cancer Discov 4(5): 554-563, 2014.

34 Yu Z, Xie G, Zhou G, Cheng Y, Zhang G, Yao G, Chen Y, Li Y and Zhao G: NVP-BEZ235, a novel dual PISK-mTOR inhibitor displays anti-glioma activity and reduce chemoresistance to temozolomide in human glioma cells. Cancer Lett 367(1): 58-68, 2015.

35 Ströbele S, Schneider M, Schneele L, Siegelin MD, Nonnenmacher L, Zhou S, Karpel-Massier G, Westhoff MA, Halatsch ME and Debatin KM: A potential role for the inhibition of PIK3 signaling in glioblastoma therapy. PLoS One 10(6): e0131670, 2015.

36 Kahn J, Hayman TJ, Jamal M, Rath BH, Kramp T, Camphausen $\mathrm{K}$ and Tofilon PJ: The mTORC1/mTORC2 inhibitor AZD2014 enhances the radiosensitivity of glioblastoma stem-like cells. Nature Oncol 16(1): 29-37, 2014.

37 Blumenthal DT, Dvir A, Lossos A, Tzuk-Shina T, Lior T, Limon D, Yust-Katz S, Lokiec A, Ram Z, Ross JS, Ali SM, Yair R, Soussan-Gutman L and Bokstein F: Clinical utility and treatment outcome of comprehensive genomic profiling in high grade glioma patients. J Neurooncol 130(1): 211-219, 2016.

38 Wen PY, Chang SM, Lamborn KR, Kuhn JG, Norden AD, Cloughesy TF, Robins HI, Lieberman FS, Gilbert MR, Mehta MP, Drappatz J, Groves MD, Santagata S, Ligon AH, Yung WK, Wright JJ, Dancey J, Aldape KD, Prados KD and Ligon KL: Phase I/II study of erlotinib and temsirolimus for patients with recurrent malignant gliomas: North American Brain Tumor Consortium trial 04-02. Neuro Oncol 16(4): 567-578, 2014.

Received November 15, 2016

Revised December 9, 2016

Accepted December 15, 2016 